\title{
Urinalysis: Sediment examination, currently, a liquid kidney biopsy?
}

Glísia Mendes Tavares Gomes*

Laboratório de Diagnóstico, Ensino e Pesquisa-Centro de Saúde Escola Germano Sinval Faria/Escola Nacional de Saúde Pública Sergio Arouca (ENSP/Fiocruz), Rio de Janeiro, Brazil.

\begin{abstract}
The current article aims to assist in understanding the importance of urinalysis, more specifically, urinary sediment examination, in the diagnosis and monitoring of kidney injuries, its particularities and, especially, its most relevant characteristics: sample which is easy to obtain, low execution cost and diagnostic utility. In view of the panorama of the increase in kidney diseases in recent decades, the application of this analytical tool has been of paramount importance, which, when performed well, both in laboratory and clinic, can bring great benefits to patients who use it, being these people in a risk group for chronic kidney diseases or not. The databases used for search were- PubMed, Scielo and Web of Science.
\end{abstract}

\section{Introduction}

Among the diseases that represent a major public health problem are the different types of kidney disorders that affect about 850 million people around the world [1,2]. It is believed that until 2040, chronic kidney disease (CKD) will be the fifth disease in numbers of death $[2,3]$.

CKDs can be understood as structural and functional abnormalities of the kidneys [4] for three months or more with repercussions on the general condition of the patient, with the possibility of progression to the final stage of renal failure [5].

It is well-known that there are risk groups for the development of CKD, among which we can highlight high blood pressure $(35 \%)$ and diabetic $(29 \%)$ patients $[5,6]$. Obesity increases the risk of developing chronic diseases and is associated with premature mortality. Followed by the increase in the prevalence of obesity, there was also an increase in the prevalence of arterial high blood pressure, diabetes, and cardiovascular disease, factors associated with renal failure development [7-11].

It is also important to highlight that drug nephrotoxicity is the third leading cause of acute kidney injury (AKI) [12], considering that individuals who survive an episode of AKI are at risk of developing chronic kidney disease. In addition, the mechanism that causes AKI to progress to CKD is not fully understood [13].

Often underdiagnosed, chronic kidney disease has an inaccurate prevalence, which may vary according to the population studied and the method used for its diagnosis [14]. Tuot, et al. [15], mention multifactorial issues that compromise the awareness of renal patients. Among them, the lack of an adequate approach for patients with CKD, regarding their real situation.

Nowadays, the use of increased serum creatinine as a diagnostic criterion for acute kidney injury has limitations. Therefore, urine sediment analysis can be considered a good biomarker for the evaluation of distinction between prerenal (functional) AKI and renal (intrinsic) AKI $[16,17]$.
Urine testing is emphasized as an excellent biomarker of kidney disease. We highlight the important contribution of the centrifuged urine test, evaluated by an experienced nephrologist, as a tool in the diagnosis and management of many conditions that affect the kidneys [18-28]. However, studies indicate low sensitivity and high specificity (22\% and $91 \%$, respectively) of the urinary sediment test $[17,29,30]$.

Higuchi, et al. [29], mention the importance of identification of urinary cellular casts in patients with acute kidney injury and heart failure, considering that the pathophysiology of renal failure, in patients with acute heart failure, is still insufficiently understood. Possible mechanisms include over-activation of the renin-angiotensinaldosterone system (RAAS), which can damage the kidneys via renal vasoconstriction, causing impairment of tubular epithelial cells.

Jing, et al. [31], also point out that the formation of urine, for being dependent on glomerular filtration and on the secretion and reabsorption of renal tubules and collecting ducts, has in the nephron, as a structural and functional unit of the kidney, all parts involved in the composition of the excrete. Therefore, urine can directly reflect the function and state of the urinary system.

In view of diverse evidence of how CKD is a major public health problem and how the search for effective biomarkers must be improved, urinalysis can play an important role in the diagnostic routine. However, even though urine testing has been the gold standard in laboratories for decades, the pre-analytical phase varies slightly between laboratories and there is no reference method for examining urinary sediment. In

*Correspondence to: Glísia Mendes Tavares Gomes, Laboratório de Diagnóstico, Ensino e Pesquisa-Centro de Saúde Escola Germano Sinval Faria/Escola Nacional de Saúde Pública Sergio Arouca (ENSP/Fiocruz), Rio de Janeiro, RJ, Brazil, E-mail: glisiagomes@gmail.com

Key words: sediment examination, urinalysis, cylinders, high blood pressure, diabetes mellitus, Covid-19

Received: August 08, 2020; Accepted: September 12, 2020; Published: September 16, 2020 
addition, there is a wide variation in inter- and intra-observer analyses $[21,22,25,32]$.

The purpose of this article is to highlight urinalysis as a diagnostic tool which would be accessible to everyone, as well as some correlations of findings in the assessment of routine urinary sediment examination, which can assist in the diagnosis of kidney injuries, that can often cause chronic diseases with asymptomatic evolution.

\section{Urinalysis and risk groups for kidney disease}

Cardiovascular diseases and chronic renal failure followed by hemodialysis not only burden health services, but also threaten life. Patients with diabetes and high blood pressure present an increased risk of chronic kidney disease. Urinalysis is a safe, easy, and cheap diagnostic tool and certainly useful for the differential diagnosis of acute kidney injury and chronic kidney disease [33].

Dysmorphic red blood cells related to glomerular involvement in type 2 diabetic patients have shown greater diagnostic utility than in type 1 diabetics, regarding the distinction distinguishing between diabetic nephropathy and the so-called non-diabetic kidney disease (NDRD), with NDRD presenting as the main pathological types, IgA nephropathy and membranous nephropathy [21,34-36].

In malignant hypertension, we can observe the presence of macroscopic hematuria, which can be mistaken as primary or secondary glomerulopathy. However, the rapid resolution of the kidney problem in cases of malignant hypertension with pressure control does not have the same efficiency in severe glomerulopathy, in which the patient generally does not have malignant high blood pressure and the kidney problem is not solved as fast [37].

Dysmorphic erythrocytes, cell casts, proteinuria, elevated creatinine level, or high blood pressure in the presence of microscopic hematuria should lead to suspicion about renal etiologies such as Immunoglobulin A nephropathy, Alport's syndrome, benign familial hematuria, or another nephropathy $[10,38]$.

Another relevant factor to highlight is the induction of nephropathy by crystalline aggregates. Patients with metabolic syndrome or type 2 diabetes may experience a defect in renal ammoniagenesis and consequent formation of dehydrated crystals of uric acid [39]. In addition, nephrolithiasis is a risk factor for high blood pressure [40,41].

Various systemic diseases such as diabetes, high blood pressure, lupus, among others, can damage the kidneys, making continuous monitoring of these patients necessary. Renal biopsy is an invasive procedure, not being the most appropriate intervention for monitoring these individuals. The process can be facilitated by the analysis of urinary sediment [16].

\section{Urinary sediment in kidney disease}

Mucus: The presence of mucus in the urine is considered normal. However, it may be increased in inflammatory and irritating situations of the urinary tract $[42,43]$. The formation of crystals due to urinary supersaturation can cause kidney injury and increased production of urinary mucus may be a risk factor for urolithiasis [44,45].

Crystalluria: A substantial number of kidney diseases involve crystalline microparticles that contribute to mechanisms of mechanical obstruction, local intrarenal inflammation and tissue injury [46]. Renal stones are generally formed by calcium oxalate in about $80 \%$ of cases. Crystals in regular or stone-afflicted patients often differ according to each individual regarding shape, size and phase of the crystal due to hyper saturation of lithogenic salts, urinary $\mathrm{pH}$ value and content of inhibitors and promoters [47].

A prevalence of nephrolithiasis has been reported to be $79 \%$ higher in high blood pressure individuals than in normotensive individuals [48].

Some studies also correlate the occurrence of kidney stones and bacterial infections of the urinary tract [49], the mechanism is supported by the discovery that certain bacteria have a propensity to bind to certain types of crystals, but not to others, and are also associated with an increase of crystal-crystal agglomerations. Another known mechanism is the production citrate lyase by bacteria, which could cause reduction in citrate levels in the urine, leading to supersaturation and crystal formation [50].

The development of crystals in the urinary tract can also be induced by drugs and become a risk factor for urolithiasis and other pathologies. The action of these drugs can occur by indirect mechanisms, favoring metabolic changes characterized by an increase in the concentration of crystallization promoters such as hypercalciuria, hyperuricosuria and hyperoxaluria or direct, when the drug itself or its metabolitesadministered in high doses and eliminated in the urine with solubility low-precipitate, forming crystals [23].

The great importance of assessing the presence of crystals in the urinary sediment is related to the possible occurrence of nephrolithiasis, considering that from 5 to $10 \%$ of the world population can be affected, with a higher frequency in men than in women: $13 \%$ and $7 \%$, respectively [51,52].

The mechanism for the formation of kidney stones remains unknown. However, some studies report the binding of monohydrate $\mathrm{CaOx}$ crystals (COM) to the apical surface of renal tubule epithelial cells, usually mediated by the interaction of cell crystals and microvilli, which triggers various cellular responses within these cells, including the production of reactive oxygen species (ROS), stimulating the production of signaling molecules, destruction and transformation of intracellular organelles, causing, in addition to renal injury, the intrarenal retention of these crystals and, finally, nephrolithiasis [53].

The identification and quantification of cells, cylinders and crystals present in the centrifuged urine sediment, allow the clinician to synthesize all the data and build a rational diagnosis. Regarding crystalinduced nephropathy, this is particularly true [54].

The monitoring of hereditary or acquired diseases, associated with the formation of urinary stones or acute or chronic impairment of renal function, due to the precipitation of intrarenal crystals, has a good biomarker in the observation of crystalluria [55].

Hematuria: Hematurias are common findings in routine urine tests and are not always sign of disease and can be classified as symptomatic, asymptomatic, transient or persistent and, depending on their location, into glomerular, nephrological or non-glomerular, urological origin $[56,57]$. Benign hematurias can be caused by urinary infection, benign prostatic hyperplasia, and kidney stones. Whereas malignant hematurias can be caused by neoplasms in bladder, kidney and prostate. In most cases (43-68\%), the etiology is unknown.

It is defined as the presence of 3 or more red blood cells per highpower microscopic field [20,57-60], with erythrocyte dysmorphism being established as the presence of $40 \%$ or more erythrocytes with morphological changes [61]. However, Hamadah, et al. [24], define glomerular disease as the presence of erythrocyte dysmorphism $\geq 25 \%$ of erythrocytes evaluated in between 10 to 12 per high-power field. 
Bolenz, et al. [58], emphasize the great sensitivity of the reagent strips, but draw attention to the need for microscopy, given the possibility of a false-negative result due to the ingestion of high doses of vitamin $\mathrm{C}$ [62]. Assessing the $\mathrm{pH}$ and urinary osmolarity is also extremely important, given that they can interfere with the size and shape of red blood cells [18].

Glomerular hemorrhage is classically characterized by the presence of proteinuria and red blood cell casts (RBC casts). However, not all patients with glomerulonephritis have such changes. Urinary sediment examination has been of great help in this respect due to the assessment of the erythrocyte morphology, indicating with greater precision the location of the bleeding, glomerular or non-glomerular [56].

Dysmorphic red blood cells have been associated with glomerular diseases. The observation of these red blood cells through phase microscopy is a methodology known to be superior to bright-field microscopy, according to some authors [21,24,56,63,64]. However, other researchers recognize the possibility of visualizing dysmorphic red blood cells through bright-field microscopy. Barros Silva, et al. [61], carried out a study, where they suggest reducing the condenser lens for better observation of these erythrocytes and other authors corroborate this observation of erythrocyte dysmorphism $[18,58,65]$.

Another characteristic highlighted by some authors is that the dysmorphic red blood cell presents, mainly, the shape of a "donut" with protrusions [22,24,61] (Figures 1 and 2).

Although hematuria is a common finding, there is no internationally accepted standardization or an evidence-based algorithm for its diagnostic evaluation. Therefore, all potential causes of hematuria and associated risk factors must be considered in order to identify or control an underlying disease that requires treatment $[58,66]$.

Cylindruria: Cylinders, which are important constituents of urinary sediment, may be associated with several renal disorders whose diagnosis may depend on the correct identification of these elements. These intratubular renal structures form part of the renal physiology, as a result of glomerulonephritis or because of systemic diseases $[67,68]$.

They can be classified, based on their morphology, into: hyaline, granular, waxy, adipose, cellular (hematic, leukocyte, epithelial),

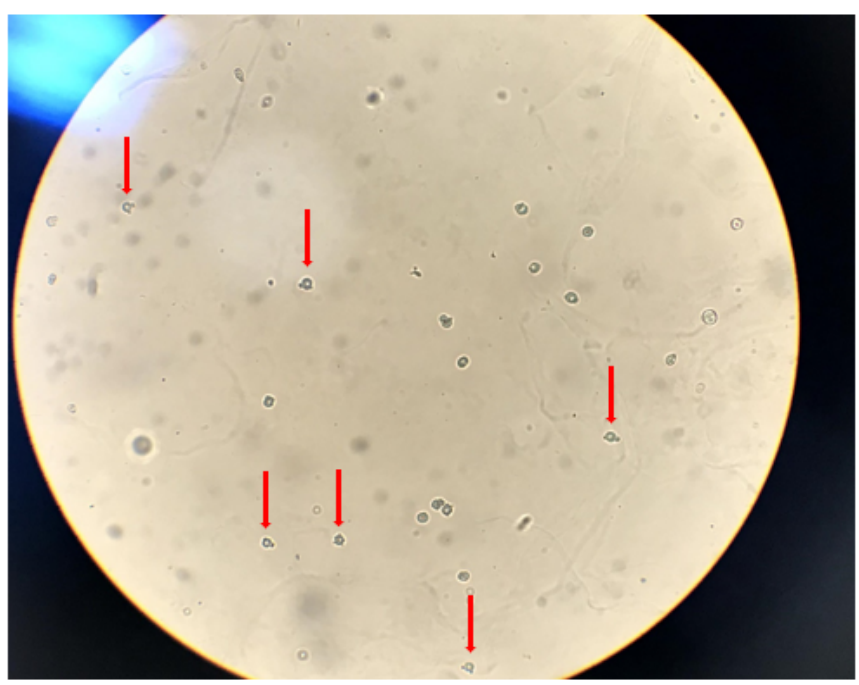

Figures 1. Red arrows: Dysmorphic red blood cells in the form of a "donut", glomerular lesion. High power field (bright field microscopy)

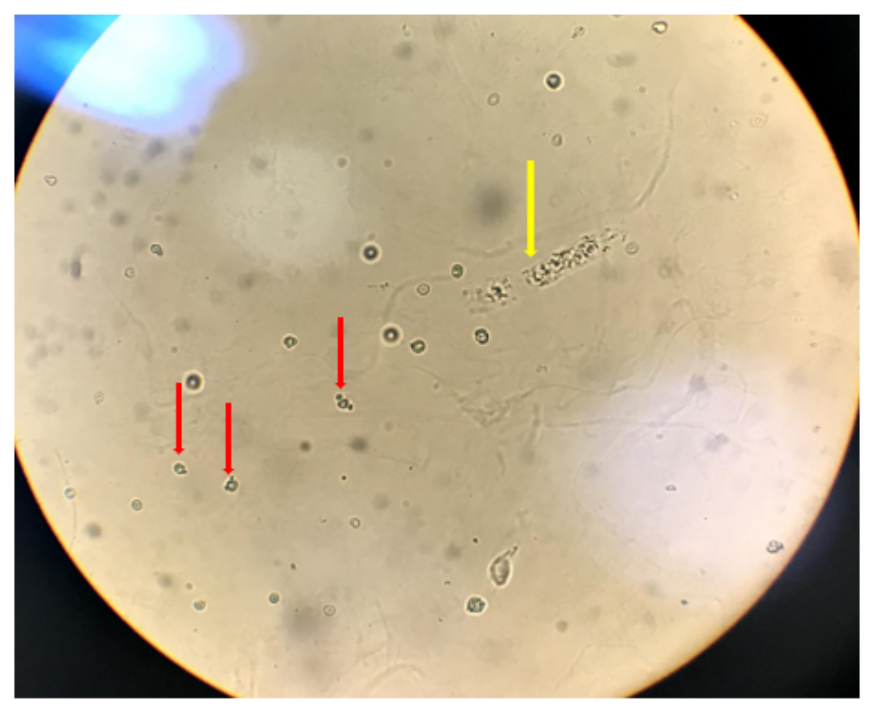

Figures 2. Red arrows: Dysmorphic red blood cells in the form of a "donut", glomerular lesion. Yellow arrow: hyaline-granular cast. High power field (bright field microscopy)

containing crystals, pigments and mixed [67,69]. While performing the microscopy, we ideally include the coverslip edges as part of the fields of view, as cylinders usually accumulate in these regions [18].

Schentag, et al. [70], observed an increased elimination of cylinders in patients using aminoglycosides, also emphasizing the importance of monitoring these patients by examining urinary sediment. In addition to reflux nephropathy, which presents large uromodulin cylinders, several other diseases exhibit different tubular cylinders, including myeloma nephropathy; crystalline nephropathy caused by drugs, phosphate, oxalate and inherited metabolic diseases; nephropathies associated with anticoagulants; bile cylinder nephropathy and rhabdomyolysis [71].

Characterized by a significant interstitial inflammatory response, the interstitial nephritis, acute onset renal dysfunction is a known risk, deriving from the use of several drugs [72], (Figures 3 and 4). A worsening of the renal function of patients with chronic kidney disease was observed, as well as in patients without underlying kidney disease, by the use of anticoagulants, visualizing the presence of RBC casts. Thus, anticoagulant-related nephropathy (ARN) is an increasingly recognized entity today, mainly through anticoagulation with warfarin [73-76].

Kanbay, et al. [77], report that the presence and number of renal tubule cells, renal tubule cell cylinders and/or granular cylinders in the urine sediment can assist in the diagnosis of acute tubular necrosis, and may also be useful to predict a more severe kidney damage, a consequence of an unsatisfactory recovery from an acute kidney injury and the need for dialysis [33]. Renal biopsies have demonstrated the presence of medication cylinders in patients with HIV and also in the use of the antibiotic, Vancomycin [78,79].

The relevance of this diagnostic tool could also be seen in cases of renal impairment by Covid-19. The first inference about the correlation between SARS and the kidneys was made after the 2003 epidemic. For the first time the transmembrane protein ACE2, expressed on the surface of several cells in our body, was identified as a viral receptor. In the kidneys, the protein is expressed in podocytes, the mesangial cell, parietal epithelium of Bowman's capsule, microvilli ("brush border") and collecting tubes [80]. 


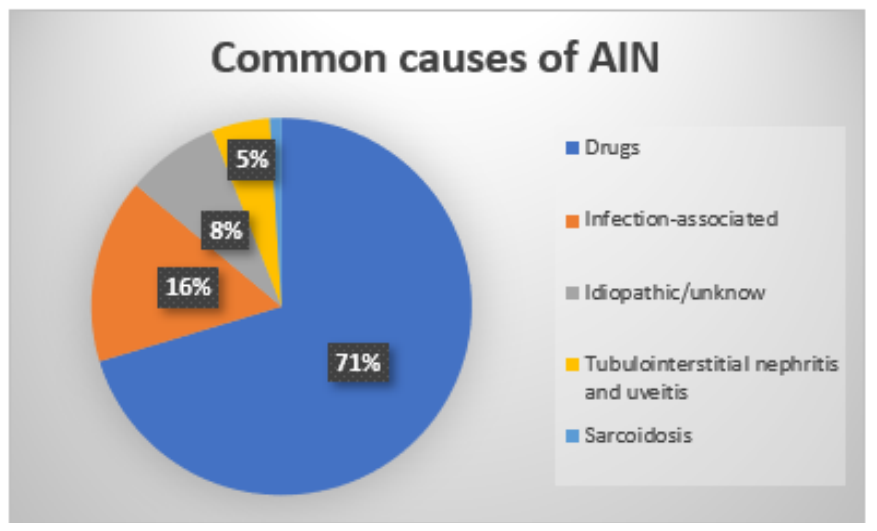

Figure 3. Most common causes of Acute Interstitial Nephritis (AIN) [72,87]

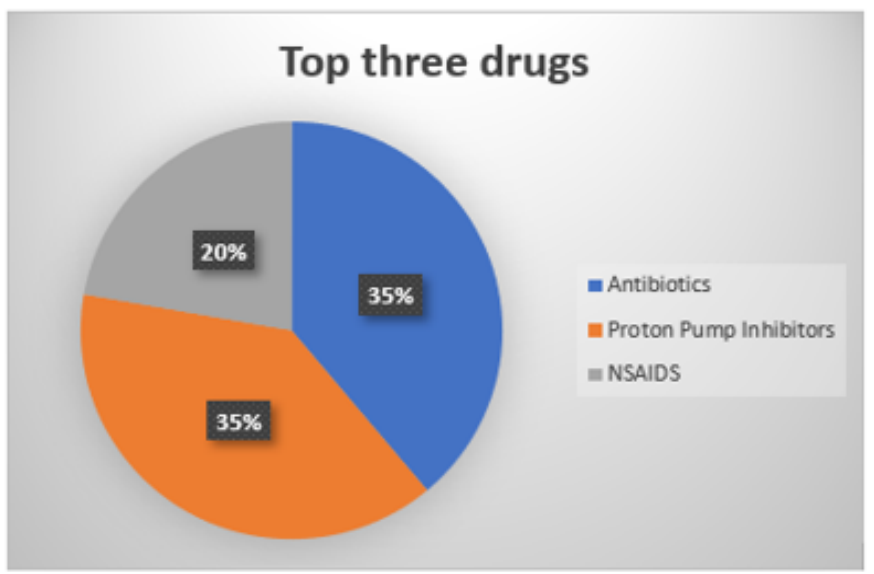

Figure 4. Three drugs most related to Acute Interstitial Nephritis (AIN) $[72,88]$

Hernandez-Arroyo, et al. [81], conducted a study by evaluating urinary sediment examination in patients with AKI associated with Covid-19 and found waxy casts in $50 \%$ of patients. The data indicated ischemic or toxic acute tubular necrosis (ATN). However, there were many misleading factors, such as the exposure of these patients to antibiotics, high blood pressure, proteinuria in the nephrotic range and pyuria or hematuria, reported by the hospital laboratory. However, despite these factors, the study strongly suggests that ATN is the primary form of AKI in Covid-19.

Two hundred and twenty-six patients with Covid-19 admitted to an Italian hospital were evaluated. Pyuria was found in $184(81.4 \%)$, $70.4 \%$ had hematuria, $49.1 \%$ presented cylinders and $31.9 \%$, hyalinegranular casts. It can be inferred from the retrospective study that renal involvement can be a significant predictor of unfavorable disease progression. The study also highlights the importance of regular urinalysis in patients with Covid-19, in view of the analysis offering important information for clinical management and risk prediction [82].

Renal epithelial cells: A healthy kidney is a relatively stable organ with little basal cell turnover. However, these cells are constantly replaced to preserve the structural and functional integrity of the kidneys. Such a mechanism may be relevant in situations of kidney injury, when there is need for cell replacement that is exceeded by the turnover of base cells [83].

Although different types of cells line each segment of the renal tubules, in urinary sediment they are hardly differentiated by morphology. Classification is restricted to erythrocytes, leukocytes, squamous and non-squamous epithelial cells [33].
Andersen, et al. [84], present a few case studies and highlight the importance of urine findings when patients are admitted. An acute tubular necrosis and acute renal failure can be evaluated, once the presence of renal tubular epithelial cells is observed, resulting from ischemic and/or nephrotoxic processes. In the sediment, renal damage can be detected before the considerable increase in creatinine figures and other blood variables.

Therefore, urinary sediment examination, based on the score of abnormal elements (granular cylinders, cells of the renal tubular epithelium), showed a sensitivity of $76 \%$ and a specificity of $86 \%$ in the prediction of the severity of renal damage, which is significantly associated with the increased risk of worsening acute kidney injury, due to chronic diseases such as diabetes and high blood pressure [16].

\section{Discussion}

The manual assessment of urinary sediment examination is still considered the gold standard. However, the growing demand in the number of samples to be analyzed in a shorter time, make way for automation and has rapidly falling out of favour among clinicians [85]. Manual analysis offers substantial information that are not contemplated in the automated essay, specially in the context of kidney injury, hematuria and nephrolithiasis [22].

The importance of accurately observing urinary cell morphology, identifying cell and acellular cylinders, recognizing various endogenous and drug-related crystals allow for a quick diagnosis of acute or chronic kidney disease. Renal tubular cells and "muddy brown" granular casts indicate ischemic and/or nephrotoxic tubular injury. Dysmorphic erythrocytes and RBC casts, as well as proteinuria and glomerular lesions. Pyuria with negative culture, renal tubule cells, leukocyte cylinders and granular cylinders suggest acute tubulointerstitial disease $[18,25,26,54,84,86]$.

Therefore, the lack in the reports of a description of dysmorphic red blood cells, inaccurate cell counts of the renal tubular epithelium and granular cylinders, by clinical analysis laboratories, are analytical gaps criticized by nephrologists [65].

Urinary microscopy is not as widely used as it should be, to the point that some laboratories do not offer the exam. Studies on urinary morphology reveal a great potential for improvement among doctors and clinical laboratory professionals, to meet the minimum requirements of the guidelines related to basic knowledge of urinary morphology $[65,84]$.

\section{Conclusion}

We cannot ignore the importance of a well-performed sediment examination that will assist the physician in the early diagnosis of an often-silent kidney injury. Therefore, the more accurate the information is, the more advantageous the examination and the evolutionary followup of this patient will be.

A more comprehensive standardization of the requirements and guidelines for performing the routine urinalysis is welcome and necessary, as well as refresher courses, mainly related to sediment examination, due to the number of possible information derived from urinary microscopy.

We are aware of the growing increase in kidney disease in recent decades, which is already a major public health problem, and, while we recognize limitations in cutting-edge technology to serve the majority 
of the population, we have a cheap, and effective exam that, when done well, is a "kidney portrait". Therefore, we have the urgent need to "make urine great again" [22].

\section{Acknowledgment}

My thanks to all the authors and thier research that served as a source for this work, especially Dr. Samira Bells, Dr. Allison Eddy, Dr. Giovani Foggazi, and Dr. Gavin Becker.

\section{References}

1. Crews DC, Bello AK, Saadi G (2019) 2019 World Kidney Day Editorial-burden, access, and disparities in kidney disease. J Bras Nefrol 41: 1-9.

2. Li PK, Garcia-Garcia G, Lui SF, Andreoli S, Fung WW, et al. (2020) Kidney health for everyone everywhere: from prevention to detection and equitable access to care. Braz J Med Biol Res 53: 3 .

3. Neuen BL, Chadban SJ, Demaio AR, Johnson DW, Perkovic V (2017) Chronic kidney disease and the global NCDs agenda. BMJ Global Health 2: 2.

4. Fernando BN, Alli-Shaik A, Hemage RK, Badurdeen Z, Hettiarachchi TW, et al. (2019) Pilot study of renal urinary biomarkers for diagnosis of CKD of uncertain etiology. Kidney Int Rep 4: 1401-1411.

5. Oliveira JGR de, Júnior GB da S, Filho JEV (2018) Chronic kidney disease: exploring new communication strategies for health promotion. Brazilian Journal in Health Promotion 31: 4.

6. dos Santos KK, Lucas TC, Glória JCR, do Carmo Júnior AP, de Cássia GR, et al. (2018) Epidemiological profile of chronic renal patients in treatment. Journal of Nursing UFPE 12: 2293-2300.

7. Ahmed MH (2010) Orlistat and calcium oxalate crystalluria: an association that needs consideration. Renal failure 32: 1019-1021.

8. Evangelista LS, Cho WK, Kim Y (2018) Obesity and chronic kidney disease: A population-based study among South Koreans. PloS one 13: e0193559.

9. Fouad M, Ismail MI, Gaballah A, Reyad E, ELdeeb S (2016) Prevalence of obesity and risk of chronic kidney disease among young adults in Egypt. Indian J Nephrol 26: 413.

10. Gaitonde DY, Cook DL, Rivera IM (2017) Chronic kidney disease: detection and evaluation. Am Fam Physician 96: 776-783.

11. Koch VH (2019) The effects of obesity on kidney function: a challenge for nephrologists. J Bras Nefrol 41: 162-165.

12. Sales GT, Foresto RD (2020) Drug-induced nephrotoxicity. Revista da Associação Médica Brasileira 66: s82-s90.

13. Pereira BJ, Barreto S, Gentil T, Assis LS, Soeiro E, et al. (2017) Risk factors for the progression of chronic kidney disease after acute kidney injury. J Bras Nefrol 39: 239-245.

14. UNASUS/UFMA - Federal University of Maranhão (2014) Risk groups for chronic kidney disease/Marcus Bastos Gomes (Org). São Luís.

15. Tuot DS, Wong KK, Velasquez A, Crews DC, Zonderman AB, et al. (2019) CKD awareness in the general population: performance of CKD-specific questions. Kidney Medicine 1: 43-50.

16. Bhagyalakshmi A, Sirisha O, Uma P, Devi P, Vijayababu P, et al. (2017) Role of urine sediment cytology in the diagnosis of renal disorders in comparison with biochemical and histopathological findings. IJRMS 2: 560-568.

17. Goldani JC, Poloni JA, Klaus F, Kist R, Pacheco LS, et al. (2020) Urine microscopy as a biomarker of Acute Kidney Injury following cardiac surgery with cardiopulmonary bypass. J Bras Nefrol 42: 18-23.

18. Cavanaugh C, Perazella MA (2019) Urine sediment examination in the diagnosis and management of kidney disease: core curriculum 2019. Am J Kidney Dis 73: 258-272.

19. Cobbaert CM, Arslan F, Martín IC, Serra AA, Picó-Plana E, et al. (2019) Automated urinalysis combining physicochemical analysis, on-board centrifugation, and digital imaging in one system: A multicenter performance evaluation of the cobas 6500 urine work area. Pract Lab Med 17: e00139.

20. Daza JL, Gutiérrez G, Vargas V, Marini A, Vavich R, et al. (2016) List of dysmorphic hematuria in gomerular diseases. J Nephrol Dial Transplant 36: 229-234.

21. Dong ZY, Wang YD, Qiu Q, Hou K, Zhang L, et al. (2016) Dysmorphic erythrocytes are superior to hematuria for indicating non-diabetic renal disease in type 2 diabetics. $J$ Diabetes Investig 7: 115-120.
22. Fonseca NM, Navarro D, Garigali G, Fogazzi GB (2019) Make Urine Great Again. Port J Nephrol Hypert 33: 205-208.

23. Guillén R, Franco L, Sánchez G, Ortíz V, Herebia L, et al. (2016) Drug induced crystalluria in the Emergency Laboratory: Report of two cases. Memorias del Instituto de Investigaciones en Ciencias de la Salud 14: 106-109.

24. Hamadah AM, Gharaibeh K, Mara KC, Thompson KA, Lieske JC, et al. (2018) Urinalysis for the diagnosis of glomerulonephritis: role of dysmorphic red blood cells. Nephrol Dial Transplant 33: 1397-1403.

25. Mcmahon GM, Waikar SS (2013) Biomarkers in nephrology. Am J Kidney Dis 62 165-178.

26. Perazella MA (2020) Is urine microscopy a useful early biomarker for cardiac surgeryrelated AKI?. J Bras Nefrol 42: 1-3.

27. Srinivasulu K, Rao KV, Kumar KP (2018) Urine analysis as a screening tool in early detection of renal abnormalities in asymptomatic school children. WJNU 7: 17-24.

28. Tsai JJ, Yeun JY, Kumar VA, Don BR (2005) Comparison and interpretation of urinalysis performed by a nephrologist versus a hospital-based clinical laboratory. $\mathrm{Am}$ J Kidney Dis 46: 820-829.

29. Higuchi S, Kabeya Y, Matsushita K, Yamasaki S, Ohnishi H, et al. (2019) Urinary cast is a useful predictor of acute kidney injury in acute heart failure. Sci Rep 9: 1-8.

30. Lima C, Macedo E (2018) Urinary biochemistry in the diagnosis of acute kidney injury. Dis Markers 2018: 1-7.

31. Jing J, Gao Y (2018) Urine biomarkers in the early stages of diseases: current status and perspective. Discov Med 25: 57-65.

32. Bunjevac A, Gabaj NN, Miler M, Horvat A (2018) Preanalytics of urine sediment examination: effect of relative centrifugal force, tube type, volume of sample and supernatant removal. Biochemia medica: Biochemia medica 28: 84-93.

33. Shukuya K, Ogura S, Tokuhara Y, Okubo S, Yatomi Y, et al. (2016) Novel round cells in urine sediment and their clinical implications. Clinica Chimica Acta 457: 142-149.

34. Kritmetapak K, Anutrakulchai S, Pongchaiyakul C, Puapairoj A (2018) Clinical and pathological characteristics of non-diabetic renal disease in type 2 diabetes patients. Clin Kidney J 11: 342-347.

35. Liang S, Zhang XG, Cai GY, Zhu HY, Zhou JH, et al. (2013) Identifying parameters to distinguish non-diabetic renal diseases from diabetic nephropathy in patients with type 2 diabetes mellitus: a meta-analysis. PloS one 8: e64184.

36. Liu S, Guo Q, Han H, Cui P, Liu X, et al. (2016) Clinicopathological characteristics of non-diabetic renal disease in patients with type 2 diabetes mellitus in a northeastern Chinese medical center: a retrospective analysis of 273 cases. Int Urol Nephrol 48: 1691-1698.

37. Hebert LA, Parikh S, Prosek J, Nadasdy T, Rovin BH (2013) Differential diagnosis of glomerular disease: a systematic and inclusive approach. Am J Nephrol 38: 253-266.

38. Sharp VJ, Barnes KT, Erickson BA (2013) Assessment of asymptomatic microscopic hematuria in adults. Am Fam Physician 88: 747-754.

39. Daudon M, Frochot V, Bazin D, Jungers P (2016) Crystalluria analysis improves significantly etiologic diagnosis and therapeutic monitoring of nephrolithiasis. Comptes Rendus Chimie 19: 1514-1526.

40. Kittanamongkolchai W, Mara KC, Mehta RA, Vaughan LE, Denic A, et al. (2017) Risk of hypertension among first-time symptomatic kidney stone formers. Clin J Am Soc Nephrol 12: 476-482.

41. Khan SR (2014) Reactive oxygen species, inflammation and calcium oxalate nephrolithiasis. Transl Androl Urol 3: 256.

42. Iosob GA, Prisecaru M, Stoica I, Comănescu L (2017) Observations on normal and pathological cytology of the urinary sediment. Studii şi Cercetări. Universitatea"Vasile Alecsandri" din Bacău 26: 75-83.

43. Nakamae DD, de Araújo CP, Miyadahira AMK, Takahashi EIU, Valente MA, et al. (1980) Exame de urina: todo o rigor na colheita de amostras. Revista da Escola de Enfermagem da USP 14: 51-57.

44. Gerharz EW, Turner WH, Kälble T, Woodhouse CR (2003) Metabolic and functional consequences of urinary reconstruction with bowel. BJU international 91: 143-149.

45. https://uroweb.org/guideline/urolithiasis Accessed on: 12 July 2020

46. Mulay SR, Shi C, Ma X, Anders HJ (2018) Novel insights into crystal-induced kidney injury. Kidney Dis 4: 49-57. 
47. Sun XY, Xu M, Ouyang JM (2017) Effect of crystal shape and aggregation of calcium oxalate monohydrate on cellular toxicity in renal epithelial cells. ACS omega 2: 60396052 .

48. Sumitra K, Pragasam V, Sakthivel R, Kalaiselvi P, Varalakshmi P (2005) Beneficial effect of vitamin $\mathrm{E}$ supplementation on the biochemical and kinetic properties of Tamm-Horsfall glycoprotein in hypertensive and hyperoxaluric patients. Nephrol Dial Transplant 20: 1407-1415.

49. Alelign T, Petros B (2018) Kidney stone disease: an update on current concepts. $A d v$ Urol 2018: 1-2.

50. Schwaderer AL, Wolfe AJ (2017) The association between bacteria and urinary stones. Ann Transl Med 5: 32.

51. Abbas W, Akram M, Sharif A (2019) Nephrolithiasis; prevalence, risk factors and therapeutic strategies: A review. Madridge J Intern Emerg Med 3: 90-95.

52. Santos FM, Peres AK, Mandotti MR, Peres LA (2017) Metabolic research in patients with nephrolitis. Einstein 15: 452-456.

53. Fong-ngern K, Vinaiphat A, Thongboonkerd V (2017) Microvillar injury in renal tubular epithelial cells induced by calcium oxalate crystal and the protective role of epigallocatechin-3-gallate. The FASEB Journal 31: 120-131.

54. Luciano RL, Perazella MA (2015) Crystalline-induced kidney disease: a case for urine microscopy. Clin Kidney J 8: 131-136.

55. Frochot V, Daudon M (2016) Clinical value of crystalluria and quantitative morphoconstitutional analysis of urinary calculi. Int J Surg 36: 624-632.

56. Vasconcellos LD, Penido MG, Vidigal PG (2005) Importance of erythrocyte dysmorphism in research on the origin of hematuria: Literature review. Jornal Brasileiro de Patologia e Medicina Laboratorial 41: 83-94.

57. Lopes MS, Magalhães CF, Neves DA, Abreu JS, Pereira M, et al. (2018) Microscopic hematuria: approach in the scope of primary health care. PJGPF 34: 327-333.

58. Bolenz C, Schröppel B, Eisenhardt A, Schmitz-Dräger BJ, Grimm MO (2018) The investigation of hematuria. Deutsches Ärzteblatt International 115: 801.

59. Linder BJ, Bass EJ, Mostafid H, Boorjian SA (2018) Guideline of guidelines: asymptomatic microscopic haematuria. Bju International 121: 176-183.

60. Yuste C, Gutierrez E, Sevillano AM, Rubio-Navarro A, Amaro-Villalobos JM, et al. (2015) Pathogenesis of glomerular haematuria. World J Nephrol 4: 185.

61. Barros Silva GE, Costa RS, Ravinal RC, Silva JS, Dantas M, et al. (2010) Evaluation of erythrocyte dysmorphism by light microscopy with lowering of the condenser lens: A simple and efficient method. Nephrol 15: 171-177.

62. Tedesco M, Casati L, Cozzi S, Vignati B, Civita F, et al. (2017) Microhematuria at point of care. NAPOC 3: 5000208.

63. Becker GJ, Garigali G, Fogazzi GB (2016) Advances in urine microscopy. Am J Kidney Dis 67: 954-964.

64. Koo KC, Lee KS, Choi AR, Rha KH, Hong SJ, et al. (2016) Diagnostic impact of dysmorphic red blood cells on evaluating microscopic hematuria: the urologist's perspective. Int Urol Nephrol 48: 1021-1027.

65. Chu-Su Y, Shukuya K, Yokoyama T, Lin WC, Chiang CK, et al. (2017) Enhancing the detection of dysmorphic red blood cells and renal tubular epithelial cells with a modified urinalysis protocol. Sci Rep 7: 40521 .

66. Moreno JA, Sevillano Á, Gutiérrez E, Guerrero-Hue M, Vázquez-Carballo C, et al (2019) Glomerular hematuria: Cause or consequence of renal inflammation?. Int J Mol Sci 20: 2205.

67. Caleffi A, Lippi G (2015) Cylindruria. Clin Chem Lab Med 53: s1471-s1477.
68. Dvanajscak Z, Cossey LN, Larsen CP (2020) A practical approach to the pathology of renal intratubular casts. Semin Diagn Pathol 37: 127-134.

69. Ringsrud KM (2001) Casts in the urine sediment. Lab Med 32: 191-193.

70. Schentag JJ, Gengo FM, Plaut ME, Danner DA, Mangione A, et al. (1979) Urinary casts as an indicator of renal tubular damage in patients receiving aminoglycosides. Antimicrob Agents Chemother 16: 468-474.

71. Stokes MB (2017) Vancomycin in the kidney-A novel cast nephropathy. $J$ Am Soc Nephrol 28: 1669-1670.

72. Eddy AA (2020) Drug-induced tubulointerstitial nephritis: hypersensitivity and necroinflammatory pathways. Pediatr Nephrol 35: 547-554.

73. Brodsky SV, Nadasdy T, Rovin BH, Satoskar AA, Nadasdy GM, et al. (2011) Warfarinrelated nephropathy occurs in patients with and without chronic kidney disease and is associated with an increased mortality rate. Kidney Int 80: 181-189.

74. Brodsky SV, Satoskar A, Hemminger J, Rovin B, Hebert L, et al. (2019) Anticoagulantrelated nephropathy in kidney biopsy: A single-center report of 41 cases. Kidney Medicine 1: 51-56.

75. Fortes P, Alves F, Silva C, Pessegueiro P (2019) Nephropathy Associated with Oral Anticoagulants: An Entity to Recognize. Intern Med 26: 52-59.

76. Kalaitzidis RG, Duni A, Liapis G, Balafa O, Xiromeriti S, et al. (2017) Anticoagulantrelated nephropathy: a case report and review of the literature of an increasingly recognized entity. Int Urol Nephrol 49: 1401-1407.

77. Kanbay M, Kasapoglu B, Perazella MA (2010) Acute tubular necrosis and pre-rena acute kidney injury: utility of urine microscopy in their evaluation-a systematic review. Int Urol Nephrol 42: 425-433.

78. Khurram MS, Alrajjal A, Ibrar W, Edens J, Sheikh U, et al. (2017) Cisplatin-induce nephrotoxicity and HIV associated nephropathy: mimickers of myeloma-like cast nephropathy. Case Rep Nephrol 2017: 1-5.

79. Tantranont N, Obi C, Luque Y, Truong LD (2019) Vancomycin nephrotoxicity: Vancomycin tubular casts with characteristic electron microscopic findings. Clin Nephrol Case Stud 7: 66.

80. Martinez-Rojas MA, Vega-Vega O, Bobadilla NA (2020) Is the kidney a target of SARS-CoV-2?. Am J Physiol Renal Physiol 318: F1454-F1462.

81. Hernandez-Arroyo CF, Varghese V, Mohamed MM, Velez JC (2020) Urinary sediment microscopy in acute kidney injury associated with COVID-19. Kidney360 10: 34067.

82. Bonetti G, Manelli F, Bettinardi A, Borrelli G, Fiordalisi G, et al. (2020) Urinalysis parameters for predicting severity in coronavirus disease 2019 (COVID-19). Clin Chem Lab Med 1: (ahead-of-print).

83. Castrop H (2019) The role of renal interstitial cells in proximal tubular regeneration. Nephron 141: 265-272.

84. Andersen H, Daae LN, Wien TN (2014) Urine microscopy--an important diagnostic tool. Tidsskrift for den Norske laegeforening: tidsskrift for praktisk medicin, ny raekke 134: 1765 .

85. Palsson R, Srivastava A, Waikar SS (2019) Performance of the automated urinalysis in diagnosis of proliferative glomerulonephritis. Kidney Int Rep 4: 723-727.

86. Nussbaum EZ, Perazella MA (2019) Diagnosing acute interstitial nephritis: considerations for clinicians. Clin Kidney J 12: 808-813.

87. Baker RJ, Pusey CD (2004) The changing profile of acute tubulointerstitial nephritis. Nephrol Dial Transplant 19: 8-11.

88. Valluri A, Hetherington L, Mcquarrie E, Fleming S, Kipgen D, et al. (2015) Acute tubulointerstitial nephritis in Scotland. QJM 108: 527-532.

Copyright: (C2020 Gomes GMT. This is an open-access article distributed under the terms of the Creative Commons Attribution License, which permits unrestricted use, distribution, and reproduction in any medium, provided the original author and source are credited. 